\title{
Are microsaccades responsible for the gap effect?
}

\author{
ALAN KINGSTONE \\ University of Alberta, Edmonton, Alberta, Canada \\ ROBERT FENDRICH and C. MARK WESSINGER \\ University of Califormia, Davis, California \\ and \\ PATRICIA A. REUTER-LORENZ \\ University of Michigan, Ann Arbor, Michigan
}

\begin{abstract}
Extinguishing a fixation point shortly before, or concurrently with, the onset of a peripheral visual target reduces the latency of saccades to that target. Saslow (1967) hypothesized that this gap effect might occur because fixation point offsets reduce the incidence of corrective microsaccades with an associated saccadic refractory period. In the present study, a robust gap effect was obtained. However, using a Purkinje image eyetracker with 1 arcmin of resolution, we found that fixation point offsets had no effect on the occurrence of microsaccades and that the occurrence of microsaccades had no impact on the magnitude of the gap effect. Microsaccades therefore do not appear to play any part in the production of the gap effect.
\end{abstract}

Saslow (1967) discovered that when a fixation point is offset prior to or coincidently with the onset of a peripheral visual target, the latency of a saccade to the target is shorter than when no offset event occurs. Extrapolating from previous investigations of microsaccades (Cornsweet, 1956; Krauskopf, Cornsweet, \& Riggs, 1960; Nachmias, 1959, 1961), Saslow proposed that this gap effect might occur because the offset of the fixation point reduces the incidence of fixation microsaccades just prior to the target onset. He reasoned that if such microsaccades have an associated saccadic refractory period, the lower incidence of these refractory periods would serve to shorten the average latency of a subject's saccadic response.

This hypothesis has never been tested, although many subsequent studies have been careful to refer to it (e.g., Fendrich, Hughes, \& Reuter-Lorenz, 1991; Kingstone \& Klein, 1993a, 1993b; Reuter-Lorenz, Hughes, \& Fendrich, 1991; Reuter-Lorenz, Oonk, Barnes, \& Hughes, 1995; L. E. Ross \& S. M. Ross, 1980; S. M. Ross \& L. E. Ross, 1981) and have yielded outcomes commensurate with it (e.g., Fendrich et al., 1991; Kingstone \& Klein, 1993a, 1993b; Klein, 1978; L. E. Ross \& S. M. Ross, 1980; S. M. Ross \& L. E. Ross 1981; Tam \& Ono, 1994; Tam $\&$ Stelmach, 1993). ${ }^{1}$ For example, Ross and Ross discovered that onset events at fixation delay saccadic reac-

This research was supported by NIH/NINDS PHS-NS1178. We gratefully acknowledge two anonymous reviewers for comments on a draft of this article. Correspondence concerning this article should be addressed to A. Kingstone, University of Alberta, Department of Psychology, P220 Biological Sciences Building, Edmonton, AB, Canada T6G 2E9 (e-mail: alan@psych.ualberta.ca). tion time (RT) but not manual RT. This finding dovetails with Saslow's theory: If an offset event at fixation reduces the probability of microsaccades, thereby facilitating saccadic RT, it follows that an onset event might increase the incidence of microsaccades, thereby increasing RT. Moreover, if one assumes that any inhibition associated with microsaccades is specific to the oculomotor system, onset events at fixation should delay saccadic responses but not responses in other modalities.

On the other hand, Reuter-Lorenz et al. (1991) have presented evidence that is inconsistent with the microsaccade hypothesis. They found that fixation offsets have no facilitatory effect on saccadic RT when subjects are instructed to direct saccadic responses away from the onset location of a peripheral target (antisaccades) but that there is a gap effect when subjects are instructed to saccade toward a peripheral target (prosaccades). Because Saslow's hypothesis predicts a refractory period that inhibits the saccade system in general, it is difficult to reconcile Saslow's theory with this outcome. This finding has, however, been the subject of some controversy. Fischer and Weber (1992) reported a gap effect for antisaccades and prosaccades alike. However, Reuter-Lorenz et al. (1995) argue that Fischer and Weber's (1992) result reflects the action of a nonspecific warning signal effect occasioned by fixation offset.

The contribution of microsaccades to the gap effect has therefore remained uncertain. Saslow's (1967) hypothesis predicts the following: (1) the refractory period due to microsaccades should lead to longer saccadic latencies on trials with microsaccades than on those without; (2) more microsaccades should occur on overlap than on gap trials; and (3) if only trials without microsaccades 
are considered, the gap effect should be reduced or eliminated. To address these interrelated predictions, we used a Purkinje image eyetracker to document the incidence of microsaccades in a gap paradigm.

\section{METHOD}

\section{Subjects}

Four naive subjects, 3 male and 1 female, with a mean age of 25 years (range, $22-30$ years), were paid $\$ 6.00 / \mathrm{h}$ for their participation. All subjects had normal or corrected-to-normal vision.

\section{Equipment}

Visual stimuli were presented at eye level on a Hewlett-Packard 1310A large-screen display with a fast (P15) phosphor CRT. A Purkinje image eyetracker with resolution of 1 arcmin was used to monitor subjects' eye motions. The subjects' right eye position was sampled, and the display screen refreshed, at $500 \mathrm{~Hz}$. A warning tone was generated by a Wavetek Model 116 function generator. The display oscilloscope, function generator, Purkinje eyetracker, and finger key were interfaced via Data Translation analog to digital (AD) and digital to analog (DA) converters with an IBM PC AT computer which controlled stimulus presentations and response tabulation.

\section{Stimuli and Procedure}

Subjects sat alone at a table in a dark testing room with their heads positioned by a bite board, $1 \mathrm{~m}$ from the display screen. They were dark adapted for approximately $5 \mathrm{~min}$ before the beginning of each testing session. Stimuli had a luminous intensity of $10 \mathrm{~cd} / \mathrm{m}^{2}$, and were shown against a nominally black $\left(<1 \mathrm{~cd} / \mathrm{m}^{2}\right)$ background. The eyetracker was calibrated at the start of each testing session, and this calibration was checked at the start of each trial block. Calibration entailed recording a subject's eye position at each of five stimulus locations: center, and $4^{\circ}$ above, below, left, and right of center. Eyetracker gains were set so that $1 \mathrm{AD}$ bit equaled 1 arcmin of eye displacement.

The appearance of an $X$ (subtending $.5^{\circ} \times .5^{\circ}$ ) in the center of the CRT screen signaled that a trial was about to begin. Subjects fixated this $\mathrm{X}$ and initiated each trial with a keypress. Following this keypress, a random time delay of $900-1,200$ msec preceded target onset. On each trial the eye was sampled for a total of $1,500 \mathrm{msec}$, beginning $800 \mathrm{msec}$ prior to target onset and continuing for $700 \mathrm{msec}$ after target onset.

The target, a plus sign subtending $.5^{\circ} \times .5^{\circ}$, was presented randomly $4^{\circ}$ to the left or right of center. On all trials, a $1280-\mathrm{Hz}$ warning tone was sounded $200 \mathrm{msec}$ before target onset. The tone was turned off when the target appeared. Subjects were instructed to maintain central fixation until the appearance of a target. They were then to make a saccadic eye movement response to the target as quickly and as accurately as possible. The target remained present for $1,000 \mathrm{msec}$. The display was then extinguished, and after an intertrial interval of $500 \mathrm{msec}$ an $\mathrm{X}$ appeared in the center of the screen signaling that the next trial was ready to begin.

There were three types of trials. In gap trials, the fixation stimulus was extinguished $200 \mathrm{msec}$ before target onset. In no-gap trials, fixation was extinguished coincidently with target onset. In overlap trials, fixation was not extinguished. Each trial type occurred equally often and at random.

Each testing session lasted about $1 \mathrm{~h}$ and comprised four blocks of 72 trials, for a total of 288 trials. Rest periods separated each block. All subjects received about 15 practice trials before testing.

\section{Data Analysis}

Eye records were analyzed off line. No filtering of the records was deemed neccesary. Microsaccades had a distinctive profile, consisting of a sudden shift in the horizontal and/or vertical position trace with a small but conspicuous overshoot and return to the new baseline position within 4-8 msec (see Figure 1). Because of their small size, we were not confident that microsaccades would be found reliably by an automatic detection algorithm, and we therefore chose to identify these saccades by visual inspection. Microsaccades of 2 arcmin or greater were easily detected. Microsaccade size was taken to be the difference between the presaccadic eye position and the postsaccadic position at the end of the overshoot. Overshoots associated with saccades are characteristic of Purkinje image eyetracker records and may be a tracker artifact. In any case, in the present investigation, they were useful insofar as they helped to make the microsaccades in our records distinctive. The latency of target directed saccades was assessed automatically using a velocity criterion $\left(50^{\circ} / \mathrm{sec}\right)$. However, in all cases, the correct identification of these responses was confirmed by visual inspection of the eye record.

The latency of microsaccadic and saccadic responses was defined in relation to target onset (e.g., a saccade that occurred before target onset was recorded as having a negative RT, and a saccade that occurred after target onset was recorded as having a positive RT). Because we did not wish to exclude any potential eye movements from our analysis, we defined those smaller than $1^{\circ}$ as microsaccades and those larger than $1^{\circ}$ as saccades. The microsaccades that we observed (see Table 1) were characteristic of those found in previous studies (cf. Ditchburn \& Foley-Fischer, 1967). If subjects executed more than one saccade in a trial, the first saccade was used during the data sort. Both the horizontal and the vertical magnitudes of microsaccades were recorded.

The data analysis was conducted as follows. Trials were excluded if there was an anticipation or direction error, or if a blink preceded a saccadic response. A saccade initiated before, or less than $100 \mathrm{msec}$ after, target onset was classified as an anticipation. A saccade executed $100 \mathrm{msec}$ or more after target onset and toward the target visual field was considered correct. A saccade was classified as a directional error when executed after target onset but to the nontarget visual field. Failure to execute a saccade within $700 \mathrm{msec}$ was considered a miss.

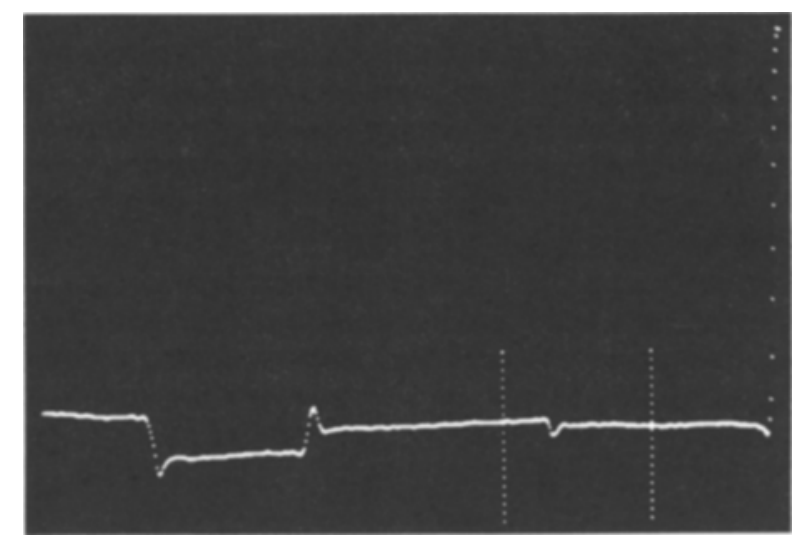

Figure 1. An illustrative horizontal eye movement record for a gap trial. One second of data is shown. The left vertical line marks the time at which the fixation point was turned off. The right vertical line marks the time at which the target appeared, $200 \mathrm{msec}$ later. The small discontinuities in the eye motion trace are microsaccades. The microsaccade that occurs within the gap interval (i.e., between the vertical lines) measures 4 arcmin. The leftmost microsaccade measures 30 arcmin. The large eye movement at the end of the record is the saccade to the target, which occurs 168 msec after target onset. 
Table 1

Incidence and Topology of Microsaccades

\begin{tabular}{|c|c|c|c|c|c|c|}
\hline \multirow[b]{2}{*}{ Subject } & \multicolumn{3}{|c|}{$\begin{array}{c}\% \text { of Trials } \\
\text { on Which Microsaccades } \\
\text { Occurred }\end{array}$} & \multicolumn{2}{|c|}{ Mean Amplitude } & \multirow{2}{*}{$\begin{array}{c}\text { Time Before Target } \\
\text { Onset }\end{array}$} \\
\hline & Overlap & No Gap & Gap & Horizontal & Vertical & \\
\hline J.F. & 0.0 & 2.1 & 1.1 & 11 & 13 & 145 \\
\hline G.M. & 14.1 & 10.4 & 10.1 & 15 & 6 & 156 \\
\hline J.E. & 0.0 & 0.0 & 0.0 & & & \\
\hline M.E. & 3.2 & 4.4 & 1.1 & 19 & 6 & 48 \\
\hline Overall & 4.3 & 4.2 & 3.1 & 15 & 8 & 116 \\
\hline
\end{tabular}

Note-Amplitude is given in arcmin; time before target onset, in milliseconds.

\section{RESULTS}

Previous investigators have found that as the temporal gap between fixation offset and target onset lengthens, saccadic RT declines, reaching asymptote at approximately $200 \mathrm{msec}$ (Saslow, 1967; L. E. Ross \& S. M. Ross, 1980; S. M. Ross \& L. E. Ross, 1981). Therefore, to test the hypothesis that microsaccades contribute to the gap effect, we looked for microsaccades on every trial within a critical interval that began 200 msec before target onset and ended with the occurrence of a saccadic response. An example of a gap trial with a microsaccade occurring within the critical interval is shown in Figure 1.

The incidence and topology of the recorded microsaccades are summarized in Table 1 . The combined data from 4 subjects ( 1,090 trials) yielded just 40 microsaccades within the critical interval. In individual subjects, the incidence of microsaccades varied from 0 to 29 ( 0 to $12 \%$ of trials). The horizontal magnitude of the microsaccades ranged from 2 to 44 arcmin, and the vertical magnitude ranged from 0 to 27 arcmin (the vertical size of 0 indicating that some microsaccades were exclusively horizontal). The average onset time of these microsaccades was $116 \mathrm{msec}$ prior to target presentation. An analysis of variance (ANOVA) revealed that the incidence of microsaccades varied significantly between subjects $[F(3,8)=37.26, p<.0001]$ but did not vary significantly between the gap conditions $[F(2,6)<1]$. The latter finding should not be interpreted as a failure to replicate previous microsaccade investigations (e.g., Cornsweet, 1956; Nachmias, 1959, 1961). Unlike in previous studies, in which the incidence of eye movements was measured over relatively long time intervals (e.g., Cornsweet, 1956, took measurements over 45 -sec intervals; Nachmias, 1959, 1961, took measurements over 30sec intervals), we confined our analysis to a brief interval critical to the gap effect beginning $200 \mathrm{msec}$ before target onset and continuing until the start of a saccadic response. Any effect of the fixation point on the frequency of microsaccades may simply not have had time to manifest itself.

To evaluate the effect of microsaccades on saccadic latencies in the overlap, no-gap, and gap conditions, we eliminated all trials with microsaccades in the interval beginning $200 \mathrm{msec}$ before target onset. The data from this subset of trials were compared with the original data set (see Figure 2). A two-way ANOVA indicated that there was a significant effect of gap condition [overlap RT $>$ no-gap RT $>$ gap RT; $F(2,6)=28.36, p<.001]$ but no effect of microsaccades $[F(1,3)=2.46, p>.20]$ and no interaction $[F(2,6)<1]$.

When this analysis was also conducted for the individual subjects, it yielded the same pattern of results. For Subject G.M., who had the greatest incidence of microsaccades, the overlap versus no-gap versus gap pattern was $226>209>190 \mathrm{msec}$ with microsaccades included, and $224>209>188 \mathrm{msec}$ with microsaccades removed, yielding a significant effect of gap condition but no effect of microsaccades. For this subject we also measured the condition mean saccadic latency of the specific trials with microsaccades $(233,209,206)$ and compared these with the condition mean values of trials without microsaccades $(224,209,188)$. In no case do these means differ statistically $(p>.20)$.

Data on saccadic accuracy and response latency are given in Table 2. An analysis of the accuracy data shows that neither error rates $[F(2,6)=3.24, p>.10]$ nor saccadic amplitudes $[F(2,6)=2.92, p>.10]$ varied significantly between conditions. Anticipations (RT $<100 \mathrm{msec}$ ) accounted for 21 of the 24 response errors executed by subjects $(1.89 \%$ of the total trials). The average amplitude of correct saccades was $4.2^{\circ}$, which is close to the optimal $4^{\circ}$ response.

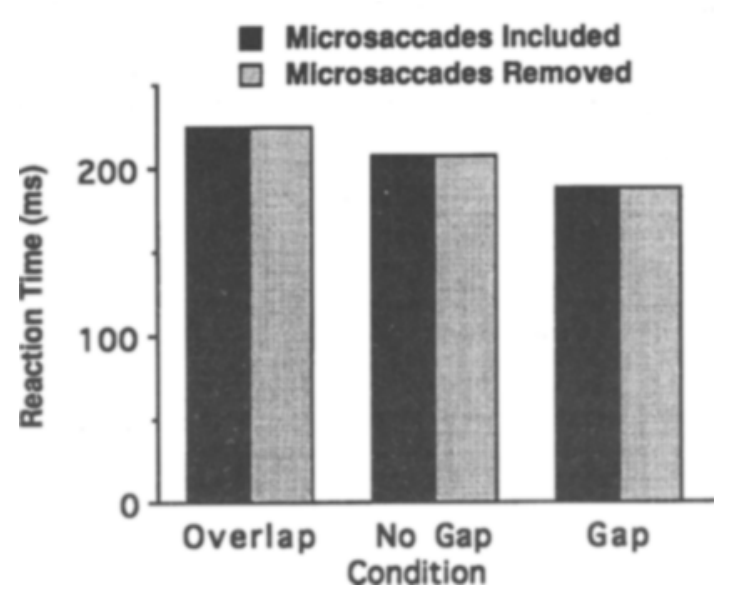

Figure 2. Saccadic latencies for overlap, no gap, and gap conditions, with and without trials containing microsaceades. 
Table 2

Saccadic Accuracy and Response Latency

\begin{tabular}{|c|c|c|c|c|c|c|c|c|c|c|c|c|}
\hline \multirow[b]{3}{*}{ Subject } & & & & & & & \multicolumn{6}{|c|}{ Latency } \\
\hline & \multicolumn{3}{|c|}{$\%$ Correct } & \multicolumn{3}{|c|}{ Amplitude } & \multicolumn{2}{|c|}{ Overlap } & \multicolumn{2}{|c|}{ No Gap } & \multicolumn{2}{|c|}{ Gap } \\
\hline & Overlap & No Gap & $\overline{\text { Gap }}$ & Overlap & No Gap & Gap & $M$ & $S D$ & $M$ & $\overline{S D}$ & $M$ & $\overline{S D}$ \\
\hline J.F. & 100.0 & 99.0 & 97.9 & 4.6 & 4.2 & 4.2 & 247 & 24.1 & 229 & 17.5 & 199 & 29.6 \\
\hline G.M. & 97.7 & 98.9 & 95.2 & 4.5 & 4.1 & 4.2 & 226 & 35.2 & 209 & 26.6 & 190 & 38.1 \\
\hline J.E. & 99.0 & 100.0 & 93.7 & 4.3 & 4.2 & 4.3 & 200 & 42.2 & 179 & 23.6 & 157 & 25.9 \\
\hline M.E. & 96.9 & 97.8 & 97.9 & 4.0 & 4.1 & 3.8 & 227 & 50.3 & 211 & 52.2 & 207 & 49.4 \\
\hline Overall & 98.4 & 98.9 & 96.2 & 4.4 & 4.2 & 4.1 & 225 & 38.0 & 207 & 30.0 & 188 & 35.8 \\
\hline
\end{tabular}

Note-Amplitude is given in degrees of arc; latency, in milliseconds.

\section{DISCUSSION}

The pattern of saccadic latencies observed in the present study replicates the original work of Saslow (1967): RTs are fastest when fixation offset precedes target onset by $200 \mathrm{msec}$ (gap condition), longer when fixation offset and target onset coincide (no-gap condition), and slowest when there is no offset event (overlap condition). Saslow hypothesized that fixation offset facilitates RT by reducing the incidence of microsaccades that can increase RT.

We found that saccadic latencies and the gap effect were unaffected by whether subjects produced many (Subject G.M.), few (Subjects J.F. and M.E.), or no microsaccades (Subject J.E.) measured from $200 \mathrm{msec}$ before the target onset. In addition, whether and when the fixation point was offset had no effect on the incidence of microsaccades. Finally, eliminating all trials that contained microsaccades had no effect on saccadic latency for any subject in any condition. We take these findings as strong disconfirmation of the microsaccadic explanation of the gap effect.

When Saslow (1967) proposed the microsaccade hypothesis, it was known that small corrective microsaccades can occur more frequently in the presence than in the absence of a fixation stimulus (see, e.g., Cornsweet, 1956; Nachmias, 1959). There was also evidence of a refractory period following saccadic eye movements, with the latency of a second saccade increasing if the target for this saccade occurs closely in time to the initial saccade (e.g., Bartlett, Eason, \& White, 1961). Our work shows, however, that for the time interval relevant to the gap effect (e.g., $200 \mathrm{msec}$ prior to target onset) the occurrence of microsaccades is unaffected by the presence versus absence of a fixation stimulus. Moreover, we found that the magnitude of the gap effect was unaffected when only trials without microsaccades were evaluated. Finally, we found that for the subject with many microsaccades, the condition mean for trials with microsaccades did not differ from the condition mean for trials without microsaccades. This suggests that any refractory period associated with microsaccades must be very brief. Illustrating this point, Figure 3 shows a trial with a 7 -arcmin microsaccade occurring $104 \mathrm{msec}$ after target onset. The subject's saccade to the target, which has a latency of $196 \mathrm{msec}$, occurs only $80 \mathrm{msec}$ after the completion of this microsaccade. This outcome is commensurate with the possibility that microsaccades are generated at a low level in the oculomotor system (i.e., within the subcortical output stages), so that they do not interfere with the programming of goal-directed saccades.

These data appear to unequivocally disconfirm Saslow's (1967) microsaccade explanation of the gap effect. What then produces the gap effect? One hypothesis is that engaged attention inhibits the saccadic system, and that the offset of an attended stimulus (e.g., the fixation point) removes this inhibition by disengaging attention (see, e.g., Braun \& Breitmeyer, 1988, 1990; Fischer \& Breitmeyer, 1987; Mayfrank, Mobashery, Kimmig, \& Fischer, 1986). Reuter-Lorenz et al. (1991) question this hypothesis, noting that, unlike attentional disengagement, the gap effect appears to have a premotor rather than sensory-perceptual locus. Kingstone and Klein (1993a) tested the attentional predisengagement theory (APT) directly and found that, contrary to the predictions of APT, RTs were equally facilitated by attended and unattended stimulus offsets (see also Klein, Taylor, \& Kingstone, 1995; Tam \& Stelmach, 1993).

Kingstone and Klein (1993a) suggest that the gap effect might be driven by two independent processes (see also Kingstone, Klein, \& Taylor, 1994). One component

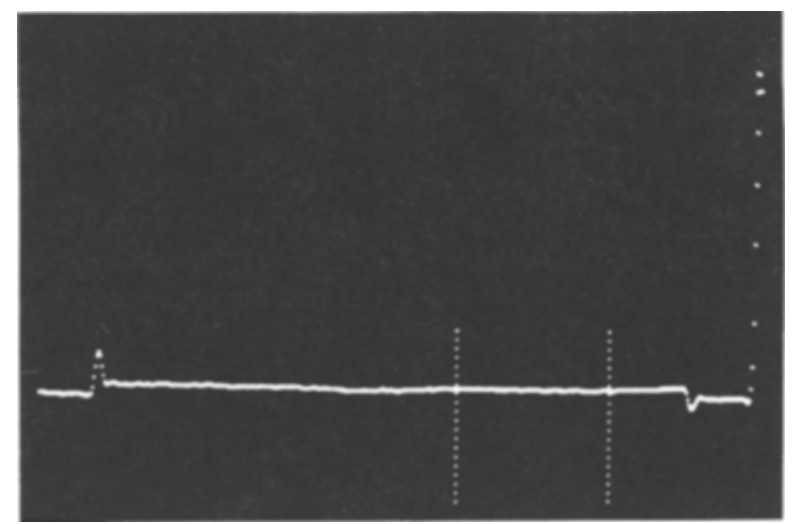

Figure 3. A horizontal eye movement (Subject M.E.) is illustrated. The left vertical line marks the time of fixation ofiset. The right vertical line marks the time of target onset, 200 msec later. A 7-ancmin microsaccade occurs 104 msec after target onset. A goal-directed saccade, with a latency of $196 \mathrm{msec}$, occurs only $80 \mathrm{msec}$ after completion of the microsaccade. 
is a general motor preparation (warning) effect produced by the onset of the gap. The other component is a fixation release effect that is specific to the oculomotor system. It is the first component, for example, that appears to produce the robust gap effect for antisaccades as reported by Fischer and Weber (1992). Reuter-Lorenz et al. (1995) found that the gap effect for antisaccades is reduced from 32 to $14 \mathrm{msec}$ if the warning signal effects of the fixation point offset are controlled for by sounding an acoustic warning tone $200 \mathrm{msec}$ before target onset in both the gap and the overlap conditions. In contrast, prosaccades show a 43-msec gap effect even with warning effects controlled.

Fendrich et al. (1991) and Reuter-Lorenz et al. (1991) have suggested that the second component, the fixation release effect, involves a facilitation of saccadic premotor processes mediated by the superior colliculus. This suggestion has recently received corroborative support from Munoz and Wurtz (1992, 1993a, 1993b; see also Hikosaka \& Wurtz, 1983). They demonstrated that chemical deactivation of the rostral pole of the superior colliculus serves to reduce saccadic latencies while electrical stimulation of this region serves to prevent either saccadic initiation or continuation. These data have led investigators to hypothesize that engaging the oculomotor system at fixation is a function of the rostral pole of the superior colliculus, and that disengaging the oculomotor system from fixation is one stage in the normal sequence of saccadic programming. Removal of a fixation stimulus may disengage this fixation system, allowing for the more efficient generation of saccades (e.g., Fendrich et al., 1991; Kingstone \& Klein, 1993a, 1993b; Reuter-Lorenz et al., 1991; Tam \& Ono, 1994; Tam \& Stelmach, 1993). To the extent that antisaccades depend on the frontal eye fields rather than a collicular-based reflex pathway (see, e.g., Guitton, Buchtel, \& Douglas, 1985), the effects of fixation release on these saccades should be minimal (Reuter-Lorenz et al., 1991; ReuterLorenz et al,, in press).

\section{REFERENCES}

Bartlett, N. R., EAson, R. G., \& White, C. T. (1961). Latency of ocular fixation upon the second of two successive stimuli. Perception \& Motor Skills, 13, 259-268.

Braun, D., \& Breitmeyer, B. G. (1988). Relationship between directed visual attention and saccadic reaction times. Experimental Brain Research, 73, 546-552.

Braun, D., \& BreItMEYER, B. G. (1990). Effects of reappearance of fixated and attended stimuli upon saccadic reaction time. Experimental Brain Research, 81, 318-324.

CARPENTER, R. H. S. (1977). Movements of the eyes. New York: Methuen.

CORNSWEET, T. N. (1956). Determination of the stimuli for involuntary drifts and saccadic eye movements. Journal of the Optical Society of America, 46, 987-993.

DitChBuRn, R. W., \& Foley-Fischer, J. A. (1967). Assembled data in eye movements. Optica Acta, 14, 113-118.

Fendrich, R., Hughes, H. C., \& Reuter-Lorenz, P. A. (1991). Fixationpoint offsets reduce the latency of saccades to acoustic targets. Perception \& Psychophysics, 50, 383-387.

Fischer, B., \& BREITMEYER, B. [G.] (1987). Mechanisms of visual attention revealed by saccadic eye movements. Neuropsychologia, 25 , 73-83.
FisCHER, B., \& WEBER, H. (1992). Characteristics of "anti" saccades in man. Experimental Brain Research, 89, 415-424.

Fischer, B., \& WEBER, H. (1993). Express saccades and visual attention. Behavioral \& Brain Sciences, 16, 553-610.

Guitton, D., Buchtel, H. A., \& Douglas, R. M. (1985). Frontal lobe lesions in man cause difficulties in suppressing reflexive glances and in generating goal-directed saccades. Experimental Brain Research, 58, 455-472.

Hikosaka, O., \& Wurtz, R. H. (1983). Visual and oculomotor functions of monkey substantia nigra pars reticulata. I. Relation of visual and auditory responses to saccades. Journal of Neurophysiology, $49,1230-1253$.

INHOFF, A. W., TOPOLSKI, R., VITU, F., \& O'RegAN, J. K. (1993). Attention demands during reading and the occurrence of brief (express) fixations. Perception \& Psychophysics, 54, 814-823.

Krngstone, A., \& Klein, R. M. (1993a). Visual offsets facilitate saccadic latency: Does predisengagement of visuospatial attention mediate this gap effect? Journal of Experimental Psychology: Human Perception \& Performance, 19, 1251-1265.

KINGSTONE, A., \& KLEIN, R. M. (1993b). What are human express saccades? Perception \& Psychophysics, 54, 260-273.

KInGSTONE, A., KLEIN, R. M., \& TAYLOR, T. (1994). Visual offsets facilitate saccadic latency: There are two components to this gap effect. Unpublished manuscript.

KLEIN, R. M. (1978). Chronometric analysis of saccadic eye movements: Reflexive and cognitive control. In D. M. Landers \& R. W. Christina (Eds.), Psychology of motor behavior and sport 1977 (pp. 247-254). Champaign, IL: Human Kinetics.

Klein, R. M., TAYlor, T. L., \& Kingstone, A. (1995). Against a role for attentional disengagement in the gap effect: A friendly amendment to Tam and Stelmach (1993). Perception \& Psychophysics, 57, 573-577.

Krauskopf, J., Cornsweet, T. N., \& Riggs, L. A. (1960). Analysis of eye movements during monocular and binocular fixation. Journal of the Optical Society of America, 50, 572-578.

Mayfrank, L., Mobashery, M., Kimmig, H., \& Fischer, B. (1986). The role of fixation and visual attention in the occurrence of express saccades in man. European Archives of Psychiatry \& Neurological Science, 235, 269-275.

Munoz, D. P., \& Wurtz, R. H. (1992). Role of the rostral superior colliculus in active visual fixation and execution of express saccades. Journal of Neurophysiology, 67, 1000-1002.

Munoz, D. P., \& WuRTz, R. H. (1993a). Fixation cells in monkey superior colliculus: I. Characteristics of cell discharge. Journal of Neurophysiology, 70, 559-575.

MUNOZ, D. P., \& WURTZ, R. H. (1993b). Fixation cells in monkey superior colliculus: II. Reversible activation and deactivation. Journal of Neurophysiology, 70, 576-589.

NaChMiAs, J. (1959). Two-dimensional motion of the retinal image during monocular fixation. Journal of the Optical Society of America, 49, 901-908

NACHMIAS, J. (1961). Determinars of the drift of the eye during monocular fixation. Journal of the Optical Society of America, 51, 761766.

Reuter-Lorenz, P. A., Hughes, H. C., \& Fendrich, R. (1991). The reduction of saccadic latency by prior offset of the fixation point: An analysis of the gap effect. Perception \& Psychophysics, 49, 167-175.

Reuter-Lorenz, P. A., Oonk, H., Barnes, L., \& Hughes, H. C. (1995). Effects of warning signals and fixation point offsets on the latencies of pro- vs. anti-saccades: Implications for an interpretation of the gap effect. Experimental Brain Research, 103, 287-293.

Ross, L. E., \& Ross, S. M. (1980). Saccade latency and warning signals: Stimulus onset, offset, and change as warning events. Perception \& Psychophysics, 27, 251-257.

Ross, S. M., \& Ross, L. E. (1981). Saccadic latency and warning signals: Effects of auditory and visual stimulus onset and offset. Perception \& Psychophysics, 29, 429-437.

SasLow, M. G. (1967). Effects of components of displacement-step stimuli upon latency for saccadic eye movement. Journal of the $O p$ tical Society of America, 57, 1024-1029.

TAM, W. J., \& ONO, H. (1994). Fixation disengagement and eye-movement latency. Perception \& Psychophysics, 56, 251-260. 
TAM, W. J. \& SteLmaCh, L. B. (1993). Viewing behavior: Ocular and attentional disengagement. Perception \& Psychophysics, 54, 211 222.

Wenban-Smuth, M. G., \& Findlay, J. M. (1991). Express saccades: Is there a separate population in humans? Experimental Brain Research, 87, 218-222.

\section{NOTE}

1. It is interesting to note that Carpenter (1977) reasoned that if the variability of target-directed saccadic latencies was due to the presence versus absence of a microsaccade refractory effect, the distribution of saccadic latencies should be bimodal. Some investigators have reported that bimodal distributions are frequently observed (see, e.g., Fischer \& Weber, 1993, for a recent review) but many others have found that bimodality is not robust (e.g., Inhoff, Topolski, Vitu, \& O'Regan, 1993; Kingstone and Klein, 1993b; Reuter-Lorenz et al., 1991; Reuter-Lorenz et al., in press; Tam \& Ono, 1994; Tam \& Stelmach, 1993; Wenban-Smith \& Findlay, 1991).

(Manuscript received June 21, 1994; revision accepted for publication January 20, 1995.) 